GSA DATA REPOSITORY ITEM 2009261

Barchan Dunes Stabilized Under Recent Climate Warming on the Northern Great Plains

Stephen A. Wolfe, Chris H. Hugenholtz

\title{
Methods and Results
}

Optical ages reported by Wolfe et al. (2001) used sand-sized (90-125 and 80-250) $\mu \mathrm{m}$ K-feldspar grains with $1.4 \mathrm{eV}$ (infrared) excitation and measurement of the $3.1 \mathrm{eV}$ (violet) emission under the MAAD (Multiple Aliquot Additive Dose) protocol. Feldspar was used due to the low-light emissions of quartz grains from these sands, particularly for younger samples. This technique has been used successfully on sand dunes in the Canadian Great Plains (Wolfe et al., 2004), with ages that are in agreement with radiocarbon ages (Wolfe et al., 2002; 2008) and an optical age derived from quartz (Huntley and Lamothe, 2001). Thus, the optical ages represent accurate burial times since the last exposure of feldspar grains to sunlight. Anomalous fading tests were performed on selected samples, though corrections were not applied to calculated ages of 300 or less, due to the insignificant affect on these young ages. Complete details of the dating approach used, including a discussion of the accuracy of the ages, are contained within Wolfe et al. (2001) and David et al. (1999).

Thirty-one samples were collected from natural exposures and from shallow pits dug on the surface of stabilized dunes. Samples were only collected from dunes with 
recognized morphology and internal structure, so that the geological relevance of the optical ages was known. The stratigraphy and sedimentology of each site was described to established the origin and geomorphic significance of the deposits and to avoid bioturbated sites (refer to David et al. 1999 and Wolfe et al. 2001 for details). In addition, two modern samples were collected from active sand surfaces to test the ability of the optical dating method to give "zero" ages.

Data used to calculate each luminescence age are included in Tables DR1 and DR2. Ages were previously published in Wolfe et al. (2001), but are presented here in the context of new geomorphic interpretation central to this paper. Ages are presented according to relevance with respect to subsurface stratigraphic sections, residual dune ridges, parabolic dunes and blowouts (Table DR2). Ages are reported relative to AD 1995 (as originally reported in Wolfe et al. 2001) and in terms of absolute date in years (CE). 
Table DR1. Water content, $\mathrm{K}, \mathrm{U}$, Th, dose rate, and equivalent doses for the samples. The first K column is for the actual sample; the second is for a mixture of material collected from within $30 \mathrm{~cm}$ above and below the sample. Th contents, where not shown, were calculated using a $\mathrm{Th} / \mathrm{U}$ ratio determined from the other samples. The grain size selected was 180-250 $\mu \mathrm{m}$ for all samples except SW5-01, SW6-01, 95-01, 95$02,95-03$, and 95-04, for which it was 90-125 $\mu \mathrm{m}$.

\begin{tabular}{|c|c|c|c|c|c|c|c|}
\hline $\begin{array}{l}\text { Sample } \\
\text { ID }\end{array}$ & $\begin{array}{l}\text { Water } \\
\text { content } \\
\Delta^{(1)}\end{array}$ & $\begin{array}{l}\mathrm{K}( \pm \\
\text { whole } \\
\text { sample }\end{array}$ & $\begin{array}{l} \pm 5 \%) \\
\text { surround } \\
\text {-ings }\end{array}$ & $\begin{array}{l}\mathrm{U} \\
(\mu \mathrm{g} / \mathrm{g})\end{array}$ & \begin{tabular}{|l} 
Th \\
$(\mathrm{g} / \mathrm{g})$ \\
\pm 0.1
\end{tabular} & $\begin{array}{l}\text { Dose rate } \\
\text { (Gy/ka) } \\
\pm 0.13\end{array}$ & $\begin{array}{l}\text { Equivalent } \\
\text { dose } \\
\text { (Gy) }\end{array}$ \\
\hline $\begin{array}{l}\text { SW1-02† } \\
\text { SW2-02 } \\
\text { SW3-02† } \\
\text { SW5-01 } \\
\text { SW6-02† }\end{array}$ & $\begin{array}{l}0.037 \\
0.062 \\
0.044 \\
0.068 \\
0.051\end{array}$ & $\begin{array}{l}1.15 \\
1.43 \\
1.28 \\
1.49 \\
1.35\end{array}$ & $\begin{array}{l}1.12 \\
1.41 \\
1.29 \\
1.45 \\
1.34\end{array}$ & $\begin{array}{l}0.77 \pm 0.04 \\
1.30 \pm 0.04 \\
0.97 \pm 0.04 \\
1.08 \pm 0.04 \\
1.12 \pm 0.04\end{array}$ & $\begin{array}{l}-- \\
-- \\
2.9 \\
-- \\
--\end{array}$ & $\begin{array}{l}2.49 \\
2.93 \\
2.73 \\
2.64 \\
2.85\end{array}$ & $\begin{array}{l}0.17 \pm 0.03 \\
0.32 \pm 0.02 \\
0.25 \pm 0.01 \\
0.57 \pm 0.02 \\
0.48 \pm 0.02\end{array}$ \\
\hline $\begin{array}{l}94-23 \\
94-30^{*} \\
94-31^{*} \\
94-32^{*} \\
94-33^{*} \\
94-34^{*} \\
94-35^{*} \\
94-36^{*} \\
94-37^{*} \\
94-38^{*} \\
94-39^{*} \\
94-40^{*} \\
94-41^{*} \\
94-50 \\
94-51 \\
94-70 \\
94-71 \\
94-81 \\
94-82 \\
94-83\end{array}$ & $\begin{array}{l}0.054 \\
0.054 \\
0.060 \\
0.067 \\
0.057 \\
0.063 \\
0.065 \\
0.048 \\
0.070 \\
0.058 \\
0.062 \\
0.055 \\
0.049 \\
0.045 \\
0.040 \\
0.003 \\
0.030 \\
0.047 \\
0.063 \\
0.042\end{array}$ & $\begin{array}{l}1.18 \\
1.49 \\
1.49 \\
1.50 \\
1.48 \\
1.48 \\
1.55 \\
1.47 \\
1.48 \\
1.42 \\
1.45 \\
1.39 \\
1.39 \\
1.23 \\
1.15 \\
1.28 \\
1.40 \\
1.39 \\
1.37 \\
1.33\end{array}$ & $\begin{array}{c}--- \\
1.54 \\
1.50 \\
1.43 \\
1.50 \\
1.47 \\
1.56 \\
1.43 \\
1.48 \\
1.56 \\
1.49 \\
1.54 \\
--- \\
1.23 \\
1.14 \\
1.23 \\
1.25 \\
1.30 \\
1.38 \\
1.37\end{array}$ & $\begin{array}{l}0.86 \pm 0.05 \\
1.34 \pm 0.06 \\
1.22 \pm 0.06 \\
1.36 \pm 0.06 \\
1.33 \pm 0.06 \\
1.12 \pm 0.06 \\
1.21 \pm 0.06 \\
1.28 \pm 0.06 \\
1.35 \pm 0.06 \\
1.11 \pm 0.06 \\
1.34 \pm 0.06 \\
1.17 \pm 0.06 \\
1.06 \pm 0.09 \\
1.03 \pm 0.05 \\
0.90 \pm 0.05 \\
0.93 \pm 0.06 \\
1.02 \pm 0.06 \\
1.05 \pm 0.07 \\
1.15 \pm 0.07 \\
1.02 \pm 0.07\end{array}$ & $\begin{array}{l}- \\
- \\
\overline{3} .5 \\
- \\
- \\
- \\
- \\
3.9 \\
- \\
- \\
- \\
- \\
- \\
- \\
- \\
- \\
3.2 \\
- \\
--\end{array}$ & $\begin{array}{l}2.70 \\
3.15 \\
3.08 \\
3.13 \\
3.13 \\
3.02 \\
3.12 \\
3.11 \\
3.11 \\
2.99 \\
3.10 \\
2.99 \\
3.08^{4} \\
2.79 \\
2.66 \\
2.79^{4} \\
2.95 \\
2.83 \\
2.86 \\
2.82\end{array}$ & $\begin{array}{l}0.23 \pm 0.01 \\
0.387 \pm 0.015 \\
0.288 \pm 0.015 \\
0.363 \pm 0.019 \\
0.295 \pm 0.015 \\
0.460 \pm 0.019 \\
0.390 \pm 0.010 \\
0.542 \pm 0.019 \\
0.523 \pm 0.015 \\
0.477 \pm 0.026 \\
0.426 \pm 0.025 \\
0.351 \pm 0.019 \\
0.052 \pm 0.014 \\
0.36 \pm 0.02 \\
0.28 \pm 0.02 \\
-0.01 \pm 0.02 \\
0.27 \pm 0.02 \\
0.87 \pm 0.05 \\
0.72 \pm 0.04 \\
0.46 \pm 0.01\end{array}$ \\
\hline
\end{tabular}




\begin{tabular}{|l|l|ll|l|l|l|l|}
\hline $95-01$ & 0.035 & 1.59 & 1.57 & $1.07 \pm 0.08$ & -- & 2.88 & $0.33 \pm 0.01$ \\
$95-02$ & 0.035 & 1.55 & 1.59 & $1.12 \pm 0.09$ & - & 2.87 & $0.41 \pm 0.02$ \\
$95-03$ & 0.035 & 1.55 & 1.55 & $1.14 \pm 0.09$ & - & 2.88 & $0.37 \pm 0.01$ \\
$95-04$ & 0.035 & 1.59 & 1.59 & $1.00 \pm 0.08$ & 3.0 & 2.85 & $0.33 \pm 0.01$ \\
$95-07$ & 0.035 & 1.18 & 1.20 & $1.01 \pm 0.09$ & - & 2.74 & $0.32 \pm 0.01$ \\
$95-08$ & 0.035 & 1.31 & 1.27 & $1.00 \pm 0.08$ & 2.9 & 2.84 & $0.43 \pm 0.01$ \\
$95-10^{*}$ & 0.035 & 1.48 & 1.51 & $1.16 \pm 0.09$ & -- & 3.07 & $0.553 \pm 0.016$ \\
$95-11^{*}$ & 0.035 & 1.49 & 1.49 & $1.13 \pm 0.09$ & 3.1 & 3.04 & $0.562 \pm 0.016$ \\
\hline
\end{tabular}

${ }^{1} \Delta=$ (mass of water) / (dry mass); uncertainty is \pm 0.02 for all samples except SW6-01, for which it is \pm 0.03 .

${ }^{2} 5$-day preheat at $140^{\circ} \mathrm{C}$.

${ }^{3}$ Quartz grains: 2-day preheat at $150^{\circ} \mathrm{C}, 2.41 \mathrm{eV}$ (green) excitation.

${ }^{4}$ Dose rate used was that which would be applicable if the sample had been buried $0.5 \mathrm{~m}$. $\dagger$ Preliminary values reported by Wolfe et al. (1995) and revised herein.

* Data for dose rate and equivalent dose rate published previously by David et al. (1999). 
Table DR2. Locations, depths, and optical ages of the samples.

\begin{tabular}{|c|c|c|c|c|}
\hline Site & $\begin{array}{l}\text { Sample } \\
\text { ID }\end{array}$ & $\begin{array}{l}\text { Sample depth } \\
\text { (m) }\end{array}$ & $\begin{array}{l}\text { Age (a) } \\
\text { before } \\
\text { AD 1995) }\end{array}$ & Age (CE) \\
\hline \multicolumn{5}{|l|}{ A - Zero-age samples } \\
\hline $\begin{array}{l}\text { Burstall } \\
\text { Seward }\end{array}$ & $\begin{array}{l}94-70 \\
94-41 *\end{array}$ & $\begin{array}{l}0-0.02 \\
0-0.02 \\
\end{array}$ & $\begin{array}{l}-4 \pm 7^{1} \\
17 \pm 5^{1} \\
\end{array}$ & $\begin{array}{l}1999 \pm 7 \\
1987 \pm 5 \\
\end{array}$ \\
\hline \multicolumn{5}{|c|}{ B - Stratigraphic sections } \\
\hline $\begin{array}{l}\text { Northwest GSH } \\
\text { Burstall } \\
\text { Burstall } \\
\text { Burstall } \\
\text { Burstall } \\
\end{array}$ & $\begin{array}{l}\text { SW5-01 } \\
\text { SW6-02 } \\
94-81 \\
94-82 \\
94-83 \\
\end{array}$ & $\begin{array}{l}4.0 \\
3.0 \\
5.5 \\
3.7 \\
3.2 \\
\end{array}$ & $\begin{array}{l}216 \pm 11 \\
168 \pm 9 \\
307 \pm 21 \\
252 \pm 17 \\
163 \pm 7 \\
\end{array}$ & $\begin{array}{l}1779 \pm 11 \\
1827 \pm 9 \\
1688 \pm 21 \\
1743 \pm 17 \\
1832 \pm 7 \\
\end{array}$ \\
\hline \multicolumn{5}{|c|}{ C - Residual Dune Ridges } \\
\hline $\begin{array}{l}\text { Seward Dune } 1 \text { BR } 5 \\
\text { Seward Dune } 1 \text { RDR2 } \\
\text { Seward Dune } 1 \text { RDR3 } \\
\text { Seward Dune } 1 \text { RDR4 } \\
\text { Seward Dune 1 RDR5 } \\
\text { Seward Dune } 2 \text { BR } \\
\text { Seward Dune } 2 \text { BR } \\
\text { Seward Dune } 2 \text { BR } \\
\text { Seward Dune } 2 \text { RDR2 } \\
\text { Seward Dune } 2 \text { RDR3 } \\
\text { Seward Dune } 2 \text { RDR4 } \\
\text { Seward Dune } 2 \text { RDR5 } \\
\text { Westerham BR } \\
\text { Bigstick BR } \\
\text { Northwest GSH BR } \\
\text { Northwest GSH BR }\end{array}$ & $\begin{array}{l}94-30^{*} \\
94-31^{*} \\
94-32^{*} \\
94-33^{*} \\
94-34^{*} \\
94-35^{*} \\
95-10^{*} \\
95-11^{*} \\
94-36^{*} \\
94-37^{*} \\
94-38^{*} \\
94-39^{*} \\
94-50 \\
95-08 \\
95-02 \\
95-03\end{array}$ & $\begin{array}{l}0.5 \\
0.5 \\
0.5 \\
0.5 \\
0.5 \\
0.5 \\
1.0 \\
1.5 \\
0.5 \\
0.5 \\
0.5 \\
0.5 \\
0.5 \\
0.7 \\
0.9 \\
0.75\end{array}$ & $\begin{array}{l}123 \pm 6 \\
94 \pm 6 \\
116 \pm 7 \\
94 \pm 6 \\
152 \pm 8 \\
125 \pm 5 \\
180 \pm 8 \\
185 \pm 8 \\
174 \pm 8 \\
168 \pm 7 \\
160 \pm 10 \\
137 \pm 9 \\
129 \pm 9 \\
151 \pm 5 \\
143 \pm 9 \\
129 \pm 6 \\
\end{array}$ & $\begin{array}{l}1872 \pm 6 \\
1901 \pm 6 \\
1879 \pm 7 \\
1901 \pm 6 \\
1842 \pm 8 \\
1870 \pm 5 \\
1815 \pm 8 \\
1810 \pm 8 \\
1821 \pm 8 \\
1827 \pm 7 \\
1835 \pm 10 \\
1858 \pm 9 \\
1866 \pm 9 \\
1844 \pm 5 \\
1852 \pm 9 \\
1866 \pm 6 \\
\end{array}$ \\
\hline \multicolumn{5}{|l|}{$\mathrm{D}$ - Parabolic Dunes } \\
\hline $\begin{array}{l}\text { Seward Dune } 2 \text { BS } \\
\text { Seward } \\
\text { Westerham DH } \\
\text { Burstall DH } \\
\text { Bigstick DH } \\
\text { Bigstick DH }\end{array}$ & $\begin{array}{l}94-40 * \\
\text { SW2-02 } \\
94-51 \\
94-71 \\
94-23 \\
95-07\end{array}$ & $\begin{array}{l}0.5 \\
8.0 \\
0.5 \\
0.5 \\
0.5 \\
0.6\end{array}$ & $\begin{array}{l}117 \pm 7 \\
109 \pm 8 \\
105 \pm 8 \\
92 \pm 7 \\
85 \pm 5 \\
117 \pm 6\end{array}$ & $\begin{array}{l}1878 \pm 7 \\
1886 \pm 8 \\
1890 \pm 8 \\
1903 \pm 7 \\
1910 \pm 5 \\
1878 \pm 6\end{array}$ \\
\hline
\end{tabular}




\begin{tabular}{|l|l|l|l|l|}
\hline NW GSH DH & $95-01$ & 0.75 & $115 \pm 5$ & $1880 \pm 5$ \\
NW GSH DH & $95-04$ & 1.0 & $116 \pm 5$ & $1879 \pm 5$ \\
\hline E- Blowouts & SW1-02 & 6.0 & $68 \pm 12$ & $1927 \pm 12$ \\
\hline & SW3-02 & 4.0 & $91 \pm 5$ & $1904 \pm 5$ \\
Tunstall & Bigstick
\end{tabular}

${ }^{1}$ Dose rate used was that which would be applicable if the sample had been buried $0.5 \mathrm{~m}$. 2 -day preheat at $140^{\circ} \mathrm{C}$.

${ }^{3}$ If corrected for anomalous fading using the model described by Aitken (1985, Appendix E), and the fading data given in Table A1 of the Appendix for this sample, the age becomes $4760 \pm 330$ years.

${ }^{4}$ Quartz grains.

${ }^{5} \mathrm{DH}$, dune head; BS, backslope; BR, back ridge; DT, dune-track ridge.

$\uparrow$ Preliminary values reported by Wolfe et al. (1995) and revised herein.

* Data published previously by David et al. (1999).

\section{Dune morphology}

Sand dunes in the region are predominantly of the parabolic type. In many parts of the region back ridges connect the wings around the deflation depressions to form the upwind extension of the dunes (Fig DR1). These back ridges are typically low, arcuate sand accumulations, generally concave downwind and with an uneven crest line. Back ridges delineate the former shape and position of the back slope of individual dunes. Where dune activity and morphology has been altered back ridges can be significant chronological and morphological markers (David et al. 1999).

Many dunes in areas of high local water tables in the study region contain parallel, even-crested ridges between their wings (Fig. 2). Termed "dune-track ridges" (David 1998) and "residual dune ridges" by Levin et al (2009), these are arcuate or sometimes slightly sinuous or irregular ridges that connect the wings. Well developed examples are found in the Bigstick sand hills (Fig. DR1 A) and the Seward sand hills, where the water table fluctuates close to the ground surface. These ridges may develop when a period of 
dune migration is interrupted by more humid intervals that promote vegetation growth around the base of the dune, while the rest of the dune remains active (David 1998). With a return to more arid conditions, the dune migrates downwind and a low, vegetated ridge (lower than the corresponding back ridge) may remain at the former back base line of the dune. The even crest line of the ridge reflects the limit to which vegetation invaded the back slope of the dune. Residual dune ridges thus record only short-term climatic fluctuations, since any significant climate change would stabilize the entire dune, as is now widely observed throughout the region. In light of previous work, the ages of residual dune ridges within a particular dune should postdate the basal age of the back ridge and should become successively younger downwind (David et al. 1999). Sand deposited on the back slope, head, or slip face of a dune should, in turn, postdate the age of the dune-track ridges, as these are typically the final portions of a dune to stabilize.

Airborne LiDAR imagery for the Great Sand Hills region provides a resolution capable of discerning detailed surface topographic features that are otherwise obscured in other forms of high-resolution imagery. LiDAR imagery for the northwest Great Sand Hills (Fig. DR1 A) and the Bigstick sand hills (Fig. DR1 B), illustrate the widespread occurrence of parabolic dunes with residual dune ridges in the region interpreted as depicting the transformation of barchan to parabolic dunes.

\section{References Cited}

Aitken, M.J. 1998, An introduction to optical dating. Oxford University Press, Oxford, $267 \mathrm{pp}$. 
David, P.P., Wolfe, S.A., Huntley, D.J. and Lemmen, D.S. 1999, Activity cycle of parabolic dunes based on morphology and chronology from Seward sand hills, Saskatchewan, in Lemmen, D.S. and Vance, R.E., eds., Holocene climate and environmental change in the Palliser Triangle: a geoscientific context for evaluating the impacts of climate change on the southern Canadian Prairies: Geological Survey of Canada, Bulletin 534, p. 223-238.

Huntley, D.J., and Clague, J.J. 1996, Optical dating of tsunami-laid sands: Quaternary Research, v. 46, p. 127-140.

Huntley, D.J. and Lamothe, M. 2001, Ubiquity of anomalous fading in K-feldspars, and the measurement and correction for it in optical dating: Canadian Journal of Earth Sciences, v. 38, p. 1093-1106.

Wolfe, S.A. Huntley, D.J., David, P.P., Ollerhead, J., Sauchyn, D.J. and MacDonald, G.M. 2001, Late $18^{\text {th }}$ century drought induced sand dune activity, Great Sand Hills, Saskatchewan: Canadian Journal of Earth Sciences, v. 38, p. 105-117.

Wolfe, S.A., Huntley, D.J., and Lian, O.B. 2002, Holocene eolian activity in southcentral Saskatchewan and the southern Canadian prairies: Géographie physique et Quaternaire, v. 56, p. 215-227.

Wolfe, S.A., Huntley, D.J. and Ollerhead, J. 2004, Relict Late Wisconsinan dune fields of the northern Great Plains, Canada: Géographie physique et Quaternaire, v. 58, p. 323-336.

Wolfe, S.A., Walker, I.J. and Huntley, D.J. 2008, Late Holocene sea level regression and 
coastal evolution, Naikoon Peninsula, northeast Graham Island, Queen Charlotte Islands, British Columbia: Geological Survey of Canada, Current Research-12, $16 \mathrm{p}$. 

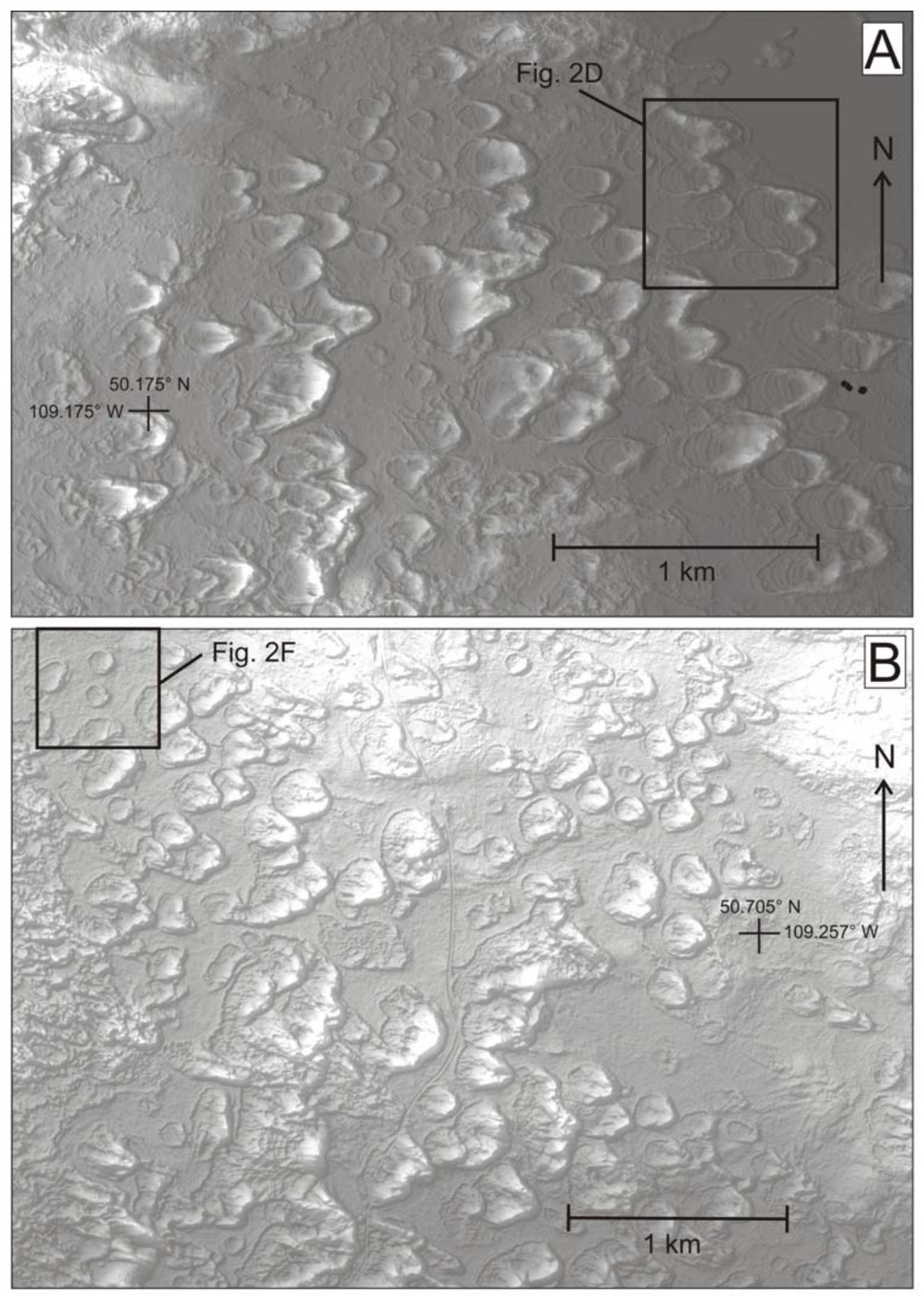

Figure DR1. LiDAR imagery of stabilized parabolic dunes with residual dune ridges interpreted as depicting the area-wide transformation of barchan to parabolic dunes: A) Bigstick sand hills (inset showing location of Figure 2D) with multiple residual dune ridges in wetland area. Area in top right corner devoid of dunes is a lake basin; B) Northwest Great Sand Hills (inset showing location of Figure 2F) depicting with mostly a single residual dune ridge (back ridge). 